\title{
Comparison between Prophylactic versus Therapeutic Doses of Low-Molecular-Weight Heparin in Severely III Coronavirus Disease 2019 Patients in Relation to Disease Progression and Outcome
}

\author{
Ahmed Elmelhat $^{\mathrm{a}}$ Essam Elbourai $^{\mathrm{b}}$ Hany Dewedar ${ }^{c}$ Taghrid Elgergawi $^{\mathrm{a}}$ \\ Maryam Alkhanboulia Salwa Ahmed ${ }^{a}$ Zoiya Malik ${ }^{a} \quad$ Alaa Nugud $^{a}$ \\ Shadha Mohammed ${ }^{a}$ Hozaifah Mohammad $^{a} \quad$ Abdullah Husain $^{a}$ \\ aLatifa Women and Children Hospital (LWCH), Dubai, United Arab Emirates; ${ }^{b}$ Rashid Hospital, \\ Dubai, United Arab Emirates; ' Dubai Thalassemia Center, Dubai, United Arab Emirates
}

\author{
Keywords \\ COVID-19 · Enoxaparin · Pneumonia · Coagulopathy · \\ Corona
}

\begin{abstract}
Introduction: The predominant coagulation abnormalities in patients with coronavirus disease 2019 (COVID-19) suggest a hypercoagulable state and are consistent with uncontrolled clinical observations of an increased risk of venous thromboembolism. Aim and Objectives: To compare the effect of prophylactic versus therapeutic doses of enoxaparin in the treatment of severe cases of COVID-19 infection. Materials and Methods: This was a retrospective observational study conducted at Latifa hospital, Dubai. Fifty-nine patients enrolled from March to June 2020 and divided into 2 groups: patients who received the prophylactic dose of enoxaparin (group 1) and patients who received the therapeutic dose of enoxaparin (group 2). Results: The mean age of all cases was $47.2 \pm 10.4$ years, while the mean weight was $76.4 \pm 13.4 \mathrm{~kg}$. Males represented $79.7 \%$ of cases. Blood group "O" was the most frequent blood group (40.9\%). None of the cases were
\end{abstract}

karger@karger.com www.karger.com/dmj

Karger $\frac{1}{\%}$

BOPEN ACCESS
(C) 2020 The Author(s)

Published by S. Karger AG, Basel

This article is licensed under the Creative Commons AttributionNonCommercial-NoDerivatives 4.0 International License (CC BYNC-ND) (http://www.karger.com/Services/OpenAccessLicense) Usage and distribution for commercial purposes as well as any distribution of modified material requires written permission. smokers or using alcohol. Bronchial asthma, lung diseases, diabetes mellitus, hypertension, CKD, cardiac disease, thyroid disease, and immunodeficiency were present in 1.7, 1.7, $39,27.1,5.1,1.7,5.1$, and $1.7 \%$ respectively. There was no significant difference between both study groups regarding personal and medical characteristics, except for hypertension where $35.9 \%$ of group 2 (therapeutic) cases were hypertensive compared to $10 \%$ of group 1 cases (prophylactic). There was a significant difference between both study groups regarding inflammatory markers improvement duration, duration of $\mathrm{MV}$ and $\mathrm{O}_{2}$ support duration, with longer duration among (therapeutic) group 2 cases compared to group 1 cases (prophylactic). There was a highly significant difference between both study groups regarding ICU admission, as $64 \%$ of group 1 cases were admitted compared to $25 \%$ of group 1 cases. Similarly, $38.5 \%$ of group 2 cases needed MV compared to only $10 \%$ of group 1 cases, which was statistically significant. There was no significant difference between both groups regarding bleeding tendency and mortality ( $p$ value 0.54 ). Conclusion: Our results showed that use of prophylactic dose of enoxaparin might have some benefits compared to the therapeutic dose in terms of less 
duration of ICU and hospital stay, duration of oxygen support, need and duration of MV, and normalization of inflammatory markers. However, there was no significant difference between the 2 regimens regarding the mortality.

(c) 2020 The Author(s).

Published by S. Karger AG, Basel

\section{Introduction}

Coronaviruses are enveloped, single positive-strand RNA viruses belonging to the large subfamily Coronavirinae, which can infect humans as well as animals [1]. SARS-CoV-2, one of the $7 \mathrm{CoVs}$ known to cause human disease, was identified in December 2019 after sequencing clinical samples from a cluster of patients with pneumonia in Wuhan, China [2].

The disease caused by SARS-CoV-2 is named coronavirus disease 2019 (COVID-19). It can present as asymptomatic, mild, moderate, severe, and critical. Given the novelty of the virus, there is still much to discover. Since its first report in December 2019 in Wuhan, China, COVID-19 was declared a pandemic by the World Health Organization (WHO) on March 11, 2020 [3].

The most common complications noted in patients who died of COVID-19 were sepsis (100\%), respiratory failure (98\%), ARDS (93\%), septic shock (70\%), acute cardiac injury (59\%), heart failure (52\%), coagulopathy (50\%), secondary infection (50\%), and acute kidney injury (50\%) [4].

A progressive increase of inflammation and an unusual trend of hypercoagulation have been observed in patients with severe and critical COVID-19 disease. This hypercoagulable state has been termed thrombo-inflammation or COVID-19-associated coagulopathy by some experts. It appears to be distinct from disseminated intravascular coagulation (DIC), though DIC has also been reported in severely affected patients. Uncontrolled clinical observations of an increased risk of venous thromboembolism are consistent with observations of a hypercoagulable state $[5,6]$.

\section{Materials and Methods}

\section{Study Design}

This was a retrospective cohort study of adult patients admitted to Latifa Women and Children's Hospital (LWCH), Dubai, UAE, between March and May 2020 during the COVID-19 pandemic and diagnosed with severe COVID-19 pneumonia. The probability of morbidity and mortality was assessed by APACHE II score
Table 1. Minor and major criteria to diagnose severe COVID-19 pneumonia

\section{Minor criteria}

Patients with respiratory rate $>30$ breaths $/ \mathrm{min}$

Multilobar infiltrates in the chest X-ray

Confusion/disorientation

Uremia (blood urea nitrogen level $\geq 20 \mathrm{mg} / \mathrm{dL}$ )

Leukopenia (white blood cells $<4,000$ cells $/ \mu \mathrm{L}$ )

Thrombocytopenia (platelet count $<100,000 / \mu \mathrm{L}$ )

Hypothermia (core temperature $<36^{\circ} \mathrm{C}$ )

Hypotension requiring aggressive fluid resuscitation

Severe respiratory distress

$\mathrm{SpO}_{2} \leq 93 \%$ on room air

Major criteria

Septic shock with need for vasopressors

Respiratory failure requiring mechanical ventilation

COVID-19, coronavirus disease 2019.

and Sepsis-Induced Coagulopathy (SIC) scores that ranged from 4 to 11 and 2 to 3 , respectively.

\section{Patient Selection}

All patients admitted to Latifa Women and Children's Hospital, Dubai, UAE, during the study period and diagnosed with severe COVID-19 infection were included in the study. To begin with, there were 60 patients diagnosed as having severe COVID-19, and 1 patient was excluded from the study, as the patient did not receive enoxaparin; therefore, the final sample consisted of 59 patients. During the study period, there were 59 admissions in Latifa Hospital that met the inclusion criteria. The patients included in the study had 1 major or 3 (or more) minor criteria as shown in Table 1. The exclusion criteria included mild-to-moderate COVID-19 pneumonia and patients with bleeding diathesis.

\section{Data Collection}

The data were collected from the computerized registry database. Patients were categorized into 2 groups; the first group (prophylactic dose group) included 20 patients who received the prophylactic dose of enoxaparin (40 mg once per day), while the second group (therapeutic dose group) included 39 patients who received the therapeutic dose of enoxaparin ( $1 \mathrm{mg} / \mathrm{kg}$ twice per day).

Demographic data, including age, weight, sex, nationality, and blood groups, were collected from all study participants. Comorbidities like diabetes mellitus, hypertension, cardiac disease, chronic pulmonary diseases, CKD, immunodeficiency, or risk factors such as smoking and alcohol consumption were included as well.

\section{Other Data Collected}

The data on the levels of inflammatory markers (CRP, procalcitonin, WBCs count $\left[<4 \times 10^{3} / \mu \mathrm{L}\right]$, lymphopenia $\left[<1 \times 10^{3} / \mu \mathrm{L}\right]$, and thrombocytopenia $\left.\left[<100 \times 10^{3} / \mu \mathrm{L}\right]\right)$, lactate dehydrogenase $(\mathrm{LDH})$, and ferritin; renal function tests; liver function tests; Ddimer; and coagulation profile were collected at the time of admis- 
Table 2. Description of personal and medical characteristics among all cases

\begin{tabular}{|c|c|c|c|c|}
\hline & $\begin{array}{l}\text { Prophylactic } \\
\text { mean } \pm \mathrm{SD} / \\
N(\%)\end{array}$ & $\begin{array}{l}\text { Therapeutic } \\
\text { mean } \pm \mathrm{SD} / \\
N(\%)\end{array}$ & $\begin{array}{l}\text { Total } \\
\text { mean } \pm \mathrm{SD}(\min -\max ) / \\
N(\%)\end{array}$ & $p$ value \\
\hline Age, years & $47.7 \pm 10.7$ & $47.0 \pm 10.5$ & $47.2 \pm 10.4(28-71)$ & $0.817^{\ddagger}$ \\
\hline Weight, kg & $76.6 \pm 11.0$ & $76.3 \pm 14.6$ & $76.4 \pm 13.43(52-112)$ & $0.945^{\ddagger}$ \\
\hline \multicolumn{5}{|l|}{ Gender } \\
\hline Male & $18(90)$ & $29(74.4)$ & $47(79.7)$ & \multirow[t]{2}{*}{$0.192^{* *}$} \\
\hline Female & $2(10)$ & $10(25.6)$ & $12(20.3)$ & \\
\hline \multicolumn{5}{|l|}{ Blood group } \\
\hline A & $2(18.2)$ & $9(27.3)$ & $11(25)$ & \multirow[t]{4}{*}{$0.161^{* *}$} \\
\hline B & $3(27.3)$ & $10(30.3)$ & $13(29.5)$ & \\
\hline $\mathrm{AB}$ & $2(18.2)$ & $0(0)$ & $2(4.5)$ & \\
\hline $\mathrm{O}$ & $4(36.4)$ & $14(42.4)$ & $18(40.9)$ & \\
\hline \multicolumn{5}{|l|}{ Nationality } \\
\hline Indian & $11(55)$ & $20(51.3)$ & $31(52.5)$ & \multirow[t]{10}{*}{$0.435^{* *}$} \\
\hline Bangladesh & $1(5)$ & $7(17.9)$ & $8(13.6)$ & \\
\hline Pakistan & $2(10)$ & $5(12.8)$ & $7(11.9)$ & \\
\hline Philippine & $1(5)$ & $3(7.7)$ & $4(6.8)$ & \\
\hline Nepal & $2(10)$ & $2(5.1)$ & $4(6.8)$ & \\
\hline UAE & $0(0)$ & $1(2.6)$ & $1(1.7)$ & \\
\hline Syrian & $1(5)$ & $0(0)$ & $1(1.7)$ & \\
\hline Iran & $1(5)$ & $0(0)$ & $1(1.7)$ & \\
\hline Eritrea & $1(5)$ & $0(0)$ & $1(1.7)$ & \\
\hline China & $0(0)$ & $1(2.6)$ & $1(1.7)$ & \\
\hline \multicolumn{5}{|l|}{ Smoking } \\
\hline No & $20(100)$ & $26(100)$ & $46(100)$ & $\mathrm{N} / \mathrm{A}$ \\
\hline \multicolumn{5}{|l|}{ Alcohol } \\
\hline No & $20(100)$ & $18(100)$ & $38(100)$ & $\mathrm{N} / \mathrm{A}$ \\
\hline \multicolumn{5}{|l|}{$\mathrm{BA}$} \\
\hline No & $20(100)$ & $38(97.4)$ & $58(98.3)$ & \multirow[t]{2}{*}{$1.0^{* *}$} \\
\hline Yes & $0(0)$ & $1(2.6)$ & $1(1.7)$ & \\
\hline \multicolumn{5}{|l|}{ Lung disease } \\
\hline No & $20(100)$ & $38(97.4)$ & $58(98.3)$ & \multirow[t]{2}{*}{$1.0^{* *}$} \\
\hline Yes & $0(0)$ & $1(2.6)$ & $1(1.7)$ & \\
\hline \multicolumn{5}{|c|}{ Diabetes mellitus } \\
\hline No & $13(65)$ & $23(59)$ & $36(61)$ & \multirow[t]{2}{*}{$0.653^{*}$} \\
\hline Yes & $7(35)$ & $16(41)$ & $23(39)$ & \\
\hline \multicolumn{5}{|l|}{ Hypertension } \\
\hline No & $18(90)$ & $25(64.1)$ & $43(72.9)$ & \multirow[t]{2}{*}{$0.034^{*}$} \\
\hline Yes & $2(10)$ & $14(35.9)$ & $16(27.1)$ & \\
\hline \multicolumn{5}{|l|}{ CKD } \\
\hline No & $19(95)$ & $37(94.9)$ & $56(94.9)$ & \multirow[t]{2}{*}{$1.0^{* *}$} \\
\hline Yes & $1(5)$ & $2(5.1)$ & $3(5.1)$ & \\
\hline \multicolumn{5}{|l|}{ Cardiac disease } \\
\hline No & $20(100)$ & $38(97.4)$ & $58(98.3)$ & \multirow[t]{2}{*}{$1.0^{* *}$} \\
\hline Yes & $0(0)$ & $1(2.6)$ & $1(1.7)$ & \\
\hline \multicolumn{5}{|l|}{ Thyroid disease } \\
\hline No & $20(100)$ & $36(92.3)$ & $56(94.9)$ & \multirow[t]{2}{*}{$0.544^{* *}$} \\
\hline Yes & $0(0)$ & $3(7.7)$ & $3(5.1)$ & \\
\hline Immunodeficie & & & & \\
\hline No & $20(100)$ & $38(97.4)$ & $58(98.3)$ & $1.0^{* *}$ \\
\hline Yes & $0(0)$ & $1(2.6)$ & $1(1.7)$ & \\
\hline
\end{tabular}


Table 3. Description of clinical presentation and laboratory findings among all cases

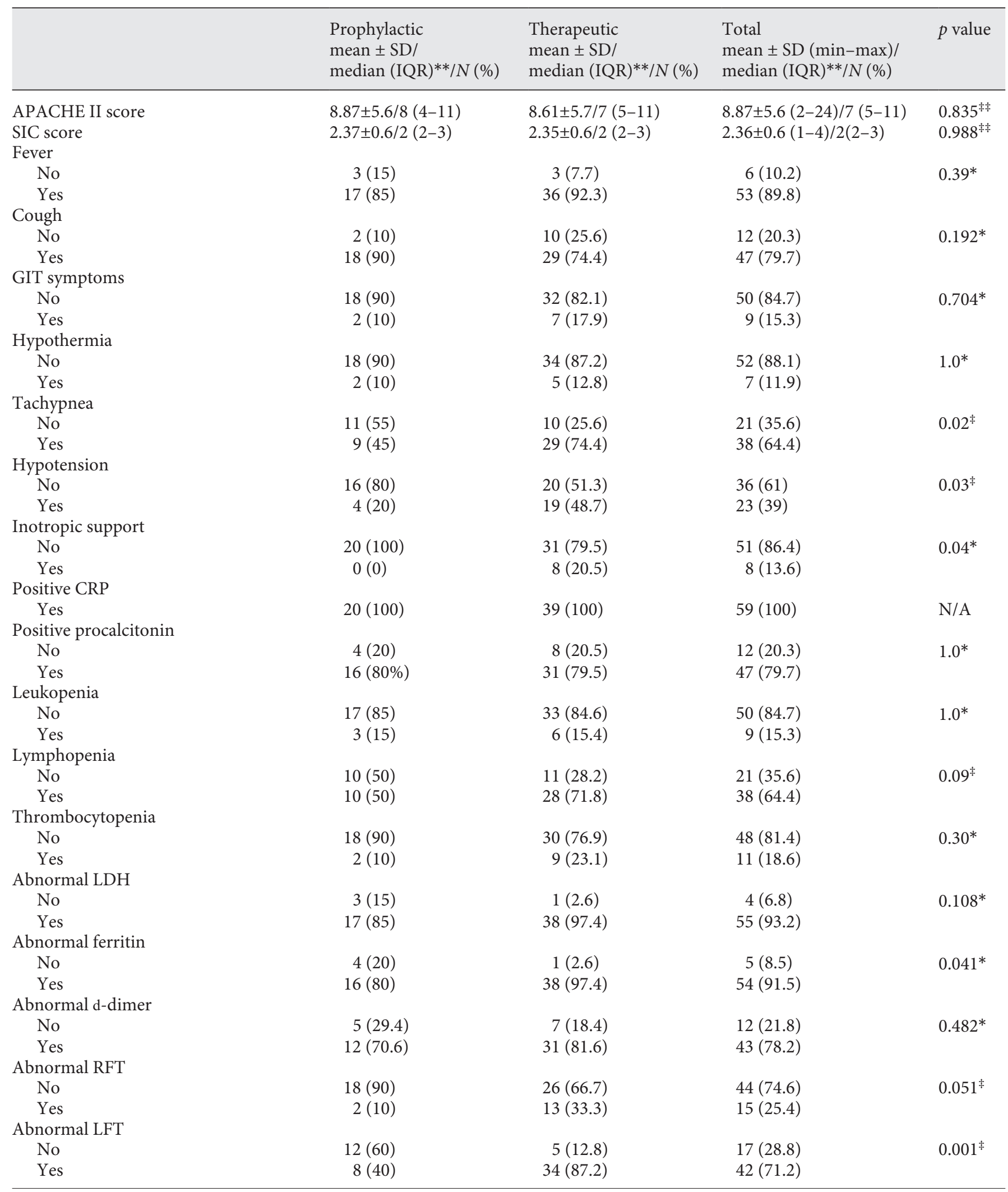


Table 3 (continued)

\begin{tabular}{lccc}
\hline & $\begin{array}{l}\text { Prophylactic } \\
\text { mean } \pm \mathrm{SD} / \\
\text { median }(\mathrm{IQR})^{* *} / N(\%)\end{array}$ & $\begin{array}{l}\text { Therapeutic } \\
\text { mean } \pm \mathrm{SD} / \\
\text { median }(\mathrm{IQR}) * * / N(\%)\end{array}$ & $\begin{array}{l}\text { Total } \\
\text { mean } \pm \mathrm{SD}(\mathrm{min}-\mathrm{max}) / \\
\text { median }(\mathrm{IQR}) * * / N(\%)\end{array}$ \\
\hline $\begin{array}{l}\text { Abnormal coagulation profile } \\
\text { No }\end{array}$ & $11(68.8)$ & $20(52.6)$ & $31(57.4)$ \\
$\begin{array}{l}\text { Yes } \\
\text { Multilobar infiltrations } \\
\text { No }\end{array}$ & $5(31.3)$ & $18(47.4)$ & $23(42.6)$ \\
Yes & $1(5)$ & $0(0)$ & $1(1.7)$ \\
\hline
\end{tabular}

SIC, Sepsis-Induced Coagulopathy; LDH, lactate dehydrogenase; RFT, renal function tests; LFT, liver function tests. ${ }^{\ddagger} \chi^{2}$ tests. \# Mann-Whitney test. ${ }^{*}$ Fisher's exact tests. ${ }^{* *}$ Interquartile range.

sion and discharge to evaluate the time taken to improve compared with clinical improvement.

\section{Statistical Analysis}

Data were revised, coded, entered on a computer, and analyzed using SPSS package version 20. Quantitative data were tested for normality with the Shapiro-Wilk test and described as mean, standard deviation (SD), or median/interquartile range according to data distribution. The Student $t$ test and Mann-Whitney test were used for comparing quantitative variables between 2 study groups. Qualitative data were expressed as frequencies $(n)$ and percentage $(\%)$. The $\chi^{2}$ and Fisher exact tests were used to test the association between qualitative variables. $p$ value $\leq 0.05$ was considered significant.

\section{Outcome of the Study}

The primary objective was to compare the effect of the 2 dose regimens of enoxaparin (prophylactic and therapeutic) on the outcome including the morbidity and mortality. The secondary objective was to observe the clinical outcome by measuring various variables including the duration of hospital stay, the need and duration of ICU admission, the need and duration of oxygen supply, the need for mechanical ventilation, and the development of side effects such as bleeding tendency.

\section{Results}

During the study period, 59 patients with severe COVID-19 pneumonia were tested, of which 20 patients were included in the first group (prophylactic dose group) and 39 patients were included in the second group (therapeutic dose group). The mean age of all patients was $47.2 \pm 10.4$ years, ranging between 28 and 71 years, while the mean weight of study cases was $76.4 \pm 13.4 \mathrm{~kg}$, ranging between 52 and $112 \mathrm{~kg}$. Of the 59 patients, $79.7 \%$ of cases were males. More than half of the cases were of Indian ethnicity (52.5\%). Blood group "O" was the most frequent blood group among cases (40.9\%). None of the cases were smokers or alcohol consumers. Bronchial asthma, lung diseases, diabetes mellitus, hypertension, CKD, cardiac disease, thyroid disease, and immunodeficiency was present in 1.7, 1.7, 39, 27.1, 5.1, 1.7, 5.1, and $1.7 \%$, respectively. Except for hypertension which was present in $35.9 \%$ of cases in group 2 (therapeutic dose) compared to $10 \%$ of cases of group 1 (prophylactic dose), as shown in Table 1, there was no other significant difference between both study groups in regard to personal and medical characteristics (Table 2).

Table 3 shows the clinical presentation and the laboratory findings in all patients. Probability of morbidity and mortality and tendency for sepsis-induced coagulopathy were assessed by APACHE II and SIC scores, with a mean of $8.87 \pm 5.6$ and $2.36 \pm 0.6$, respectively. There was no significant difference between the 2 groups regarding the APACHE II and SIC scores with $p$ values 0.835 and 0.988 , respectively. The most common presenting symptom was fever in 53 cases $(89.8 \%)$. All 59 patients $(100 \%)$ had positive CRP, while procalcitonin was positive in 47 cases (79.7\%); leukopenia, 9 cases (15.3\%); lymphopenia, 38 cases (64.4\%); thrombocytopenia, 11 cases (18.6\%); abnormal LDH, 55 cases (93.2\%); abnormal ferritin, 54 cases (91.5\%); abnormal D-dimer, 43 cases (78.2\%); abnormal renal function test, 15 cases (25.4\%); abnormal liver function test, 42 cases (71.2\%); and abnormal coagulation profile, 23 cases (42.6\%). Multilobar involvement was seen in 58 cases (98.3\%) in chest X-ray. As shown in Table 3, there was a significant difference when it came to tachypnea, hypotension, and the need for inotropic support between the 2 study groups. The significant difference in the laboratory findings in the 2 groups regarding the abnormal ferritin and liver function tests is also shown in Table 3. 
Table 4. Description of clinical outcomes among all cases

\begin{tabular}{|c|c|c|c|c|c|c|c|}
\hline Clexane duration & $9.6 \pm 7.5$ & $10(6-10)$ & $18.4 \pm 13.7$ & $14(9-24)$ & $15.41 \pm 12.59(1-60)$ & $11(8-20)$ & $0.001^{\ddagger}$ \\
\hline LDH normalization & $9.8 \pm 4.3$ & $10(6-13.5)$ & $16.3 \pm 13$ & $10.5(8-23)$ & $13.7 \pm 10.8(4-47)$ & $10(6-15)$ & $0.28^{\ddagger}$ \\
\hline Ferritin normalization & $7.7 \pm 4.2$ & $7(5-9)$ & $16.7 \pm 9.7$ & $16.5(5-25)$ & $12.9 \pm 8.95(2-32)$ & $12(5-18)$ & $0.002^{*}$ \\
\hline Duration of MV & $8.1 \pm 3.1$ & $7.5(7-10)$ & $18.6 \pm 11$ & $19(9-26)$ & $14.85 \pm 5.98(6-27)$ & $15(12-17)$ & $0.001^{\ddagger}$ \\
\hline CXR improving & $11 \pm 3$ & $11(8-13)$ & $13.9 \pm 8.1$ & $11(9-17)$ & $12.98 \pm 6.94(3-34)$ & $11(9-15)$ & $0.454^{\ddagger}$ \\
\hline \multirow[t]{2}{*}{ Duration of hospital stay } & $15.6 \pm 6.2$ & $14.5(11-18.5)$ & $24.4 \pm 13.5$ & $20(15-31)$ & $21.42 \pm 12.23(7-59)$ & $18(13-27)$ & $0.007^{\ddagger}$ \\
\hline & \multicolumn{2}{|l|}{$N(\%)$} & \multicolumn{2}{|l|}{$N(\%)$} & \multicolumn{2}{|l|}{ Total N (\%) } & $p$ value \\
\hline No & \multicolumn{2}{|l|}{$2(10)$} & \multicolumn{2}{|l|}{$0(0)$} & \multicolumn{2}{|l|}{$2(3.4)$} & \multirow[t]{2}{*}{$0.11^{* * *}$} \\
\hline Yes & $18(90)$ & & $39(100)$ & & $57(96.6)$ & & \\
\hline \multicolumn{8}{|l|}{ MV } \\
\hline No & \multicolumn{2}{|l|}{$18(90)$} & \multicolumn{2}{|l|}{$24(61.5)$} & $42(71.2)$ & & \multirow[t]{2}{*}{$0.02^{* *}$} \\
\hline Yes & $2(10)$ & & $15(38.5)$ & & $17(28.8)$ & & \\
\hline \multicolumn{8}{|l|}{ Bleeding } \\
\hline No & \multicolumn{2}{|l|}{$20(100)$} & \multicolumn{2}{|l|}{$36(92.3)$} & \multicolumn{2}{|l|}{56 (94.9) } & \multirow[t]{2}{*}{$0.54^{* * *}$} \\
\hline Yes & $0(0)$ & & $3(7.7)$ & & $3(5.1)$ & & \\
\hline \multicolumn{8}{|l|}{ Outcome } \\
\hline Died & \multicolumn{2}{|l|}{$0(0)$} & \multicolumn{2}{|l|}{$3(7.7)$} & $3(5.1)$ & & \multirow[t]{2}{*}{$0.54^{* * *}$} \\
\hline Lived & $20(100)$ & & $36(92.3)$ & & $56(94.9)$ & & \\
\hline
\end{tabular}

LDH, lactate dehydrogenase. ${ }^{*}$ Mann-Whitney test. ${ }^{\ddagger}$ Interquartile range. ${ }^{*}$ Student’s $t$ test. ${ }^{* *} \chi^{2}$ tests. ${ }^{* * *}$ Fisher’s exact tests.

Clinical outcome is shown in Table 4; out of 59 patients, 3 patients died and 30 cases $(50.8 \%)$ needed ICU admission. The median for the duration of enoxaparin use was 11 days; LDH, ferritin, and D-dimer started to improve in 10,12, and 11 days, respectively. Median duration for oxygen support and mechanical ventilation was 11 and 15 days, respectively. The median of hospital stay and chest X-ray improvement was 18 and 11 days, respectively.

There was a significant difference between both study groups in enoxaparin duration, time to ferritin and Ddimer improvement, and the duration of $\mathrm{MV}$ and $\mathrm{O}_{2}$ support duration, with longer duration among group 2 cases (therapeutic dose) compared to group 1 (prophylactic dose) in all the above-mentioned variables. There was a highly significant difference between both study groups regarding ICU admission, as $64 \%$ of the group 2 cases were admitted compared to only $25 \%$ of the group 1 cases. Similarly, $38.5 \%$ of the group 2 cases needed mechan- ical ventilation compared to only $10 \%$ of the group 1 cases, which was statistically significant. There was no significant difference between the 2 groups regarding the bleeding tendency and mortality ( $p$ value 0.54 ).

\section{Discussion}

The continuous increase in the number of people infected with COVID-19 virus has helped to improve our understanding of the disease pathogenesis. It has been observed that there are coagulation abnormalities suggesting a hypercoagulable state. Fifty-nine patients met the criteria to be included in our study. Our study compared the effect of different dose regimens of the anticoagulant enoxaparin (prophylactic and therapeutic) that was administered to patients with severe COVID-19 infection, and we compared the clinical outcome as well as improvement in laboratory parameters in both groups. 
The prophylactic dose used was $40 \mathrm{mg}$ once per day, while the therapeutic dose used was $1 \mathrm{mg} / \mathrm{kg}$ twice per day. Data were collected retrospectively from the patients' electronic files after getting approval from our Ethical Committee for the study.

Dubai inhabitants represent different nationalities; we found that the most affected ethnic group was Indians, while the local Emirati patients represented 1.7\% from all studied patients. The mean age was 47.2 years, and the mean weight was $76.44 \mathrm{~kg}$. Males were more commonly affected than females, and the most common blood group documented for the affected patients was "O" blood group.

The most common presenting symptom in all patients was fever, while gastrointestinal symptoms, mainly diarrhea, were the least presenting symptoms. Both APACHE II and SIC scores were used to assess probability of death, comorbidities, and tendency to develop coagulopathy, and the mean of $8.87 \pm 5.6$ and $2.36 \pm 0.6$, respectively, was found. In all patients, CRP was found to be highly positive, while procalcitonin was positive in $79.7 \%$; most of them showed minimal risk for infection, and this observation might need further investigation to compare the reliability of both inflammatory markers for diagnosis and follow-up. Lymphopenia was the most common finding in the full blood count of the patients. In the chest $\mathrm{X}$-ray, multilobar involvement was a constant finding in almost all patients.

In this study, there was no significant difference between the 2 groups regarding demographic data. Regarding the risk factors, there was no significant difference between both groups except for hypertension, which was higher in the therapeutic group. None of the tested patients were smokers or alcohol consumers.

We found that there was a longer duration of hospital stay including ICU admission, oxygen support, and mechanical ventilation in the therapeutic group cases. In addition, it took a longer duration for the inflammatory markers $\mathrm{LDH}$, ferritin, and D-dimer to improve in the therapeutic group rather than in the prophylactic group. There was no significant difference between both groups regarding the duration of improvement of chest X-ray findings.

Both dose regimens were observed to be safe, and bleeding tendency was observed in only 3 cases and it was not major bleeding. Additionally, both groups showed no significant difference regarding bleeding tendency ( $p$ value 0.54 ). In this study, both study groups showed no significant difference regarding mortality ( $p$ value 0.54 ).

Because COVID-19 is an emerging infectious disease, the optimal treatment for affected individuals has not yet been established. An early study out of the Hubei Province in China [7] suggested that in the absence of venous thromboembolic prophylaxis, 25\% of COVID-19 patients developed lower extremity deep venous thrombosis, which is higher than the $5-15 \%$ incidence seen in placebo arms of early studies of VTE prevention in medically ill hospitalized patients [8-10]. In these early studies, use of pharmacologic VTE prophylaxis reduced the incidence of VTE by up to $60 \%$ without an increase in major bleeding.

Our results are comparable with the recommendations published earlier by Cattaneo et al. that higher doses of low-molecular-weight heparin may not be necessarily more effective than prophylactic doses, considering that anticoagulant doses of heparin are not indicated for treatment of other types of thrombotic microangiopathies, which possibly share some pathogenic mechanisms with the COVID-19 microangiopathy and in some cases might be even dangerous as it can contribute to hemorrhagic component of microangiopathy [11]. A report from the National Institute for Public Health of the Netherlands recommended to initiate low dose prophylactic dose of low-molecular-weight heparin in all patients with suspected or confirmed COVID-19 infection irrespective of risk scores [12].

Connors et al. [13] suggested to manage COVID19 -associated coagulopathy as it would be for any critically ill patient and to follow the established practice of using thromboembolic prophylaxis for critically ill hospitalized patients and standard supportive care measures for those with sepsis-induced coagulopathy or DIC as current data do not suggest the use of full-intensity anticoagulation doses unless otherwise clinically indicated.

However, this study has several limitations. The small sample size and the short duration as we included patients' data for only 2 months, from March to May 2020. The study did not show the follow-up of the patients and if they developed any long-term morbidities after discharge. Thromboembolic disease was only suspected clinically, and there was no definite diagnosis by chest CT scan. Although thromboembolic disease was not detected in the studied patients, no ultrasound Doppler or CT pulmonary angiography scan was done to confirm or rule out venous thromboembolism. To the best of our knowledge, this is the first study published to compare the 2 dose regimens in the management of COVID-19 patients.

In conclusion, our results showed that use of prophylactic dose of enoxaparin might have some benefits compared to the therapeutic dose in terms of less duration of ICU and hospital stay, duration of oxygen support, need 
and duration of mechanical ventilation, and normalization of inflammatory markers. However, there was no significant difference between the 2 regimens regarding improvement of chest X-ray findings, bleeding tendency, and mortality. Further studies are needed to confirm or refute.

\section{Acknowledgement}

This work is dedicated to the spirits of all the martyrs of doctors around the world.

\section{Statement of Ethics}

All data were collected and analyzed retrospectively in this study. The study was approved by the Dubai Scientific Research Ethics Committee (DSREC) of the Dubai Health Authority (DHA) with reference No. DSREC-05/2020_18.

\section{Conflict of Interest Statement}

The authors have no potential conflicts of interest to disclose.

\section{Funding Sources}

There was no funding.

\section{Author Contributions}

A.E.: design, conception, data acquisition, manuscript drafting, critical analysis, and final approval. E.E.: conception, analysis, manuscript drafting, critical analysis, and final approval. H.D.: conception, data analysis, manuscript drafting, critical analysis, and final approval. T.E.: analysis, conception, manuscript drafting, critical analysis, and final approval. M.A.: data collection, manuscript drafting, critical analysis, and final approval. S.A.: data collection, manuscript drafting, critical analysis, and final approval. Z.M.: data collection, manuscript drafting, critical analysis, and final approval. A.N.: data collection, manuscript drafting, critical analysis, and final approval. S.M.: data collection, manuscript drafting, critical analysis, and final approval. H.M.: data collection, manuscript drafting, and final approval. A.H.: data collection, manuscript drafting, and final approval.

\section{References}

1 Coronaviridae Study Group of the International Committee on Taxonomy of V. The species severe acute respiratory syndromerelated coronavirus: classifying $2019-\mathrm{nCoV}$ and naming it SARS-CoV-2. Nat Microbiol. 2020;5(4):536-44.

2 Zhu N, Zhang D, Wang W, Li X, Yang B, Song J, et al. A Novel Coronavirus from Patients with Pneumonia in China, 2019. N Engl J Med. 2020;382(8):727-33.

3 WHO. Coronavirus disease (COVID-2019) situation reports. : https://www.who.int/ emergencies/diseases/novel-coronavirus-2019/situation-reports.

4 Zhou F, Yu T, Du R, Fan G, Liu Y, Liu Z, et al. Clinical course and risk factors for mortality of adult inpatients with COVID-19 in Wuhan, China: a retrospective cohort study. Lancet. 2020;395(10229):1054-62.

5 Available from: https://www.hematology. org/covid-19/covid-19-and-coagulopathy. Accessed 2020 Apr 20.
6 Connors JM, Levy JH. Thrombo-inflammation and the hypercoagulability of COVID-19. J Thromb Haemost. 2020.

7 Cui S, Chen S, Li X, Liu S, Wang F. Prevalence of venous thromboembolism in patients with severe novel coronavirus pneumonia. J Thromb Haemost. 2020.

8 Samama MM, Cohen AT, Darmon JY, Desjardins L, Eldor A, Janbon C, et al. A comparison of enoxaparin with placebo for the prevention of venous thromboembolism in acutely ill medical patients. Prophylaxis in Medical Patients with Enoxaparin Study Group. N Engl J Med. 1999;341(11):793-800.

9 Cohen AT, Davidson BL, Gallus AS, Lassen MR, Prins MH, Tomkowski W, et al. Efficacy and safety of fondaparinux for the prevention of venous thromboembolism in older acute medical patients: randomized placebo-controlled trial. BMJ. 2006;332(7537):325-9.
10 Leizorovicz A, Cohen AT, Turpie AG, Olsson CG, Vaitkus PT, Goldhaber SZ. Randomized, placebo-controlled trial of dalteparin for the prevention of venous thromboembolism in acutely ill medical patients. Circulation. 2004; 110(7):874-9.

11 Cattaneo M, Bertinato EM, Birocchi S, Brizio C, Malavolta D, Manzoni M, et al. Pulmonary embolism or pulmonary thrombosis in COVID-19? Is the recommendation to use highdose heparin for thromboprophylaxis justified? Thromb Haemost. 2020 Aug; 120(8): 1230-2.

12 Oudkerk M, Büller HR, Kuijpers D, van Es N, Oudkerk SF, McLoud TC, et al. Diagnosis, prevention, and treatment of thromboembolic complications in COVID-19: report of the National Institute for Public Health of the Netherlands. Radiology. 2020;297(1):E21622.

13 Connors JM, Levy JH. COVID-19 and its implications for thrombosis and anticoagulation. Blood. 2020;135(23):2033-40. 